\title{
Implementing the Precautionary Principle: Institutional Aspects
}

\subsection{Introduction}

In implementing the precautionary principle, regard needs to be had to the whole institutional context and to understandings about that institutional context. $^{1}$

Chapters 6 and 7 addressed the what, when, and how of the implementation of the precautionary approach by the International Seabed Authority (ISA). However, much remains to be said about the who, the ISA's institutional capacity to give effect to the precautionary approach. This chapter examines the extent to which the procedural challenges and those associated with protective measures, identified in the preceding chapters, can be explained by and addressed within the ISA's institutional structure. In particular, given the pending transition from the exploration to the exploitation phase it is necessary to examine the extent to which the ISA's current institutional structure facilitates or hinders the implementation of a precautionary approach to the exploration and exploitation of seabed minerals. In examining the benefits and challenges of the current institutional framework, the discussion illuminates the institutional changes needed to facilitate a precautionary approach to mineral exploitation.

The possibility for such institutional development is foreshadowed in Article 154 of the United Nations Convention on the Law of the Sea (LOsC or Convention). ${ }^{2}$ It requires the ISA Assembly to undertake, every five years, a general and systematic review of the manner in which the Area regime has operated in practice. The aim of this requirement is to provide a regular opportunity to assess whether the novel structure of the Area regime, which was designed in the abstract and in the absence of any previous practical experience, has operated as envisaged. In light of the review, Article 154 then allows the Assembly to take measures to improve the operation of the regime.

1 E. Fisher, 'Precaution, Law and Principles of Good Administration' (2005) 52 Water Science and Technology 19-24, page 24.

2 United Nations Convention on the Law of the Sea (adopted 10 December 1982, entered into force 16 November 1994) 1833 UNTS 3 .

(C) KONINKLIJKE BRILL NV, LEIDEN, 2017 | DOI 10.1163/9789004332287_009

This is an open access chapter distributed under the terms of the CC-BY-NC 4.o License 2 - 9789004332287 
The first review was due in 2000; however, the Assembly decided that after only five years in operation it was premature to consider restructuring the regime and thus no review was conducted. ${ }^{3}$ Neither has the Assembly conducted a review process in the years since, until 2015. In light of the significantly increased workload of the ISA, the pending transition to the exploitation stage, and 'the need to acquire further baseline environmental data', the ISA Secretary-General, in 2014, encouraged the Assembly to revisit Article 154. ${ }^{4}$ In July 2015, the Assembly decided to conduct such a review. ${ }^{5}$

This review assesses the performance of the ISA's organs against their mandate. ${ }^{6}$ Until now, in line with the evolutionary design of the Part XI regime, the ISA 'has been principally acting as an international organization providing meeting services to member States and expert bodies. ${ }^{7}$ This minimalist institutional capacity will likely not be sufficient for the ISA to discharge its mandate as the central entity administering seabed mining in the Area. Indeed, the interim report of the periodic review highlights a number of institutional challenges, including a lack of enforcement capacity, transparency, and focus on environmental aspects of the Mining Code. ${ }^{8}$

Against this background, the present chapter analyses the current institutional aspects relevant to the implementation of a precautionary approach by the ISA. As with the preceding chapter, this chapter builds upon the elements necessary to implement precaution, identified in Chapter 2.5. For the present analysis, these can be divided into two tasks: (a) mechanisms for the assessment of environmental risks and the selection of protective measures; and (b) mechanisms for ensuring compliance by the contractors with the regulatory framework.

In the first part of this chapter, Section 8.2, these tasks are discussed individually with a view to determining the extent to which they are provided for within the ISA's current institutional framework. The discussion identifies strengths but also shortcomings, mainly with respect to the Legal and Technical Commission and the ISA Secretariat. The capacity and limitations

3 ISA, ISBA/7/A/2 (18 May 2001), paragraph 6.

4 ISA, ISBA $/ 20 / \mathrm{A} / 2$ (4 June 2014), paragraph 93.

5 ISA, ISBA $/ 21 / A / 9$ (24 July 2015); ISA, ISBA $/ 21 / A / 9 / R e v .1$ (29 September 2015).

6 Ibid.

7 Allen L. Clark, Jennifer Cook Clark, and Sam Pintz, Towards the Development of a Regulatory Framework for Polymetallic Nodule Exploitation in the Area (Technical Study: No. 11) (ISA, 2013), page 39 .

8 David Johnson et al., Periodic Review of the International Seabed Authority pursuant to UNCLOS Article 154-Interim Report (ISA, 2016) <https://www.isa.org.jm/files/documents/ EN/22Sess/Art154/Art154_InterimRep.pdf>. 
of both of these organs are then analysed in Section 8.3. Based on this discussion, Section 8.4 examines two options for institutional innovation, an Environmental Commission and a Mining Inspectorate, which could address some of the challenges identified throughout this study.

\subsection{Institutional Mechanisms for Implementing Precaution}

\subsubsection{Mechanisms for the Assessment of Environmental Risks and Protective Measures}

A crucial requirement for implementing the institutional dimension of the precautionary principle is the existence of an entity competent to evaluate scientific knowledge relevant for seabed mining, assess the environmental risks of mining activities, and compare various protective measures. This includes risk assessment on a regional and global scale through strategic environmental assessments as well as project-specific environmental impact assessments. Each of these is discussed individually in the following paragraphs.

As examined in Chapter 7.2.1, strategic environmental assessments are not formally part of the ISA's procedural framework. Consequently, no entity within the ISA is specifically assigned the responsibility to coordinate and conduct such strategic assessments. However, the Environmental Management Plan for the Clarion-Clipperton Zone (EMP-CCZ) ${ }^{9}$ represents a first step towards regional scale management. Using the EMP-CCZ as an example allows for an examination of the current institutional arrangements concerning regional scale management.

As discussed in Chapter 6.3.1, although the Council decided on the adoption of the EMP-CCZ, it was the experts in the Legal and Technical Commission (LTC) who drafted the plan and recommended its adoption. However, the drafting of the EMP-CCZ was initiated by, and ultimately based on the recommendations of, external scientists. Workshops held by the ISA Secretariat provided the platform for scientists to make recommendations to the ISA with respect to particular environmental aspects that require scientific research as well as options for collaborative research projects. ${ }^{10}$ Based on the knowledge

9 ISA, ISBA $/ 17 /$ LTC $/ 7$ (13 July 2011), paragraph 15 (EMP-CCZ).

10 ISA, Prospects for International Collaboration in Marine Environmental Research to Enhance Understanding of the Deep Sea Environment, Proceedings of the ISA workshop held in Kingston (29 July-2 August 2002) (ISA, 2006); ISA, Standardization of Enviornmental Data and Information-Development of Guidelines, Proceedings of the ISA Workshop held in Kingston (25-29 June 2001) (ISA, 2002). 
gained from collaborative research, scientists then recommended the establishment of nine protected areas in the Clarion-Clipperton Zone. These recommendations were developed through external workshops organised by the scientific community as well as a Technical Study commissioned by the ISA Secretariat. ${ }^{11}$ This brief summary demonstrates that, although not formally embedded in the ISA's institutional structure, external scientists play a significant role in the work of the ISA. Technical studies and workshops provide an important, semi-formalised exchange between scientists and the LTC as well as the ISA Secretariat. It also illustrates that scientific advice, both from the scientific community and from the LTC, was central to the ISA's development of the EMP-CCZ. The ISA's institutional framework assigns a central role to scientific and technical experts, which is a prominent example of precautionary institutional design. ${ }^{2}$

However, in addition to privileging scientific advice, precautionary decision-making also requires the identification of uncertainties, particularly in the context of selecting protective measures and indeed strategic environmental objectives. These must be informed by subjective judgments as to the value placed by the public on deep ocean minerals, ecosystems, and biodiversity. ${ }^{13}$ As established in Chapter 7.4.2, the ISA's decision-making process provides for very limited participation by the public, namely through observer status for NGOs and two stakeholder surveys conducted in 2014 and 2015. At an institutional level, the ISA's framework does not currently integrate public participation. Furthermore, the Assembly, as the most representative organ, is not involved in the selection of protective measures or determination of conservation objectives.

A further point worth mentioning is that, as discussed in Chapter 2.3.3, precautionary decision-making requires potential protective measures to be assessed for their proportionality and effectiveness in achieving the desired level of protection. Whether the ISA's institutional framework provides adequate mechanisms for these tasks is difficult to determine, given that they are not included in the ISA's decision-making process. The ISA has not yet developed a conservation objective against which the proportionality and effectiveness

11 Craig R. Smith et al., Biodiversity, Species Ranges, and Gene Flow in the Abyssal Pacific Nodule Province: Predicting and Managing the Impacts of Deep Seabed Mining (Technical Study No. 3) (ISA, 2008).

12 David Freestone and Ellen Hey, 'Implementing the Precautionary Principle: Challenges and Opportunities' in David Freestone and Ellen Hey (eds) The Precautionary Principle and International Law: the Challenge of Implementation (Kluwer Law International, 1996) 249-168, page 264 . 
of individual protective measures could be judged. Although the Council's and the LTC's general mandates allow these bodies to address the proportionality and effectiveness of specific protective measures, the absence of procedures to that effect hinders this process.

With respect to the assessment of risks presented by a specific mining project, through an environmental impact assessment (EIA), a very limited number of actors are involved. It will be recalled from Chapter 5.4.1 that contractors must gather environmental baseline data, prepare environmental assessments, and continuously monitor the effects of their activities on the marine environment. Within the Authority, it is the Legal and Technical Commission that assesses new applications for exploration contracts, which include preliminary EIAS, ${ }^{14}$ and evaluates the contractors' EIAS required prior to specific exploration activities. ${ }^{15}$ The responsibility for these tasks rests exclusively with the LTC. The Council has no access to application documents from prospective contractors, even though it decides whether to approve new applications. With respect to the EIAs required during a contractor's exploration period, it is unclear whether these are accessible for the Council and the Assembly. The Exploration Regulations merely foresee the submission of EIAs as well as environmental baseline and monitoring data to the Secretary-General who transmits the information to the LTC. ${ }^{16}$ Although the Regulations also require environmental data and information to be treated as non-confidential, ${ }^{17}$ no such data and information has been made publically available by the ISA.

This illustrates a clear institutional focus on the small expert body of 24 individuals, the LTC, with little oversight by other ISA organs or indeed civil society groups or the scientific community. As a result, "[l]ack of transparency of the work of the LTC has been heavily criticised.' ${ }^{18}$

\footnotetext{
14 Chapter $3 \cdot 5 \cdot 2$

15 Chapter 5.4.1.

16 Regulations on Prospecting and Explorationfor Polymetallic Nodules in the Area, ISBA/6/A/18 (13 July 2000), amended by ISBA/19/C/17 (22 July 2013), ISBA/19/A/12 (25 July 2013), and ISBA/20/A/9 (24July 2014) (Nodules Exploration Regulations), regulation 31, annex IV section; Regulations on Prospecting and Exploration for Polymetallic Sulphides in the Area, ISBA/16/A/12/Rev.1 (15 November 2010), amended by ISBA/19/A/12 (25 July 2013) and ISBA/20/A/10 (24 July 2014) (Sulphides Exploration Regulations), regulation 33, annex IV section 5; Regulations on Prospecting and Exploration for Cobalt-rich Ferromanganese Crusts in the Area, ISBA/18/A/11 (27 July 2012), amended by ISBA/19/A/12 (25 July 2013) (Crusts Exploration Regulations), regulation 33, annex IV section 5.

17 Nodules Exploration Regulations, regulations 7, 36(2); Sulphides Exploration Regulations, regulations 7, 38(1); Crusts Exploration Regulations, regulations 7, 38(2).

18 Johnson et al. (n. 8), page 2.
} 


\subsubsection{Mechanisms for Ensuring Compliance}

A further important step in implementing a precautionary approach that has institutional implications is that of ensuring compliance with environmental standards. In the ISA context, there is a considerable lack of transparency with respect to compliance by contractors with their obligations, including their environmental obligations. As pointed out in 2014 by two delegations in the Council in the context of discussing extensions for current exploration contracts: 'it would be useful to know to what extent contractors had fulfilled the requirements of their contract thus far.'19

This statement hints at the challenge at hand; very few mechanisms are in place to oversee and ensure compliance of contractors with their contractual obligations. ${ }^{20}$ However, the reason is not a lack of competence. The ISA enjoys an extensive mandate and 'shall exercise such control over activities in the Area as is necessary for the purpose of securing compliance. ${ }^{21}$ Moreover, in the case of non-compliance, the LOSC provides for dispute settlement mechanisms and potential sanctions. ${ }^{22}$

However, the only method currently used to monitor compliance by contractors is self-reporting. Contractors are required to report annually about their exploration work carried out during the year. ${ }^{23}$ These reports are reviewed by the Legal and Technical Commission. There is no institutional capacity for other forms of monitoring compliance, despite the fact that self-reporting is a weak mechanism to ensure contractors carrying out activities in very remote marine areas fully comply with their obligations. If the ISA is to fulfil its environmental mandate properly, its powers of oversight must be significantly increased in the course of transitioning to test mining and mineral exploitation activities.

Numerous tools to monitor compliance are available, which the ISA could, in principle, apply. These include satellite tracking as an observation tool for example to ensure vessels are conducting mining activities within their contracted areas. Moreover, to monitor contractors' activities underwater, video footage from remotely operated underwater vehicles could be collected and provided to the ISA. There will no doubt be technological challenges for

19 ISA news item (July 2014) <https://www.isa.org.jm/news/seabed-council-discusses-ltcreport-gets-explanatory-note-adopts-amendments-two-regulations $>$.

20 Johnson et al. (n. 8), pages 25, 45 .

21 LOsC, article 153(4).

22 Chapter 3.6; LOSC, articles 162(2)(u), (t), 185, annex III article 18(1).

23 Exploration Regulations, annex IV section 10. 
implementing such methods but the relevant question for the present analysis is what institutional requirements would be necessary to facilitate their use.

Compliance monitoring will require a team of technical experts within the Secretariat to oversee the implementation of the technology as well as a team to evaluate the data generated by the monitoring tools. In particular, with respect to video footage, identifying irregularities and instances of noncompliance would require detailed knowledge of the conditions and limits placed on contractors. However, capacity within the currently small Secretariat is already limited, as discussed below.

The facilitation of these monitoring tools will likely require increased specialist capacity for the ISA Secretariat. Suggestions have included the establishment of a Compliance Office and a Data and Archive Centre to enable the ISA to carry out its mandate particularly in light of the transition to test mining and commercial exploitation. ${ }^{24}$ These suggestions are discussed in Section 8.4.2 below.

In addition to increasing capacity within the Secretariat, the ISA might be able to collaborate with existing monitoring projects in other sectors. For example, Global Fishing Watch is a multi-stakeholder project that provides visualised data from the Automatic Identification System of fishing vessels world-wide. ${ }^{25}$ The publicly accessible website tracks the movement of fishing vessels to show for example when vessels enter marine protected areas. Collaboration with such existing projects could allow integration of external resources into the ISA compliance structure. An additional benefit would be the opportunity to increase transparency by making the satellite data publicly available as in the case of Global Fishing Watch.

In addition to the challenges associated with ensuring compliance in general, one particular aspect requires attention, namely the inspection of mining installations. The ISA is specifically mandated to inspect all installations used by contractors in the Area. ${ }^{26}$ The standard terms for exploration contracts also foresee such inspections to monitor the effects of mining operations on the marine environment. ${ }^{27}$

In comparison, although the Antarctic Treaty also allows inspections of all stations, installations, equipment, ships, and aircrafts in Antarctica, these

\footnotetext{
24 Clark, Cook Clark, and Pintz (n. 7), page 78.

25 See <http://www.globalfishingwatch.org >.

26 LOSC, articles 153(5); 162(2)(z); Exploration Regulations, annex IV section 14.3.

27 Exploration Regulations, annex IV section 14.1(b); see also ISA, ISBA/19/LTC/8 (1 March 2013), paragraph 12.
} 
are carried out by nationals of the contracting parties. ${ }^{28}$ Similarly, inspection mandates are used in the fisheries context, for example allowing coastal states to send observers on vessels and to establish inspection schemes. ${ }^{29}$ Regional Fisheries Management Organisations have also developed observer programmes and inspection schemes not only to collect catch data but also to monitor compliance with conservation and management measures, although these programmes and schemes are carried out by the member states. ${ }^{30}$

The LOSC provides for inspections by the ISA itself, in line with its mandate to act on behalf of humankind. ${ }^{31}$ However, the Convention is somewhat ambiguous with respect to the institutional arrangements for such inspections. The Council has a supervisory role and can 'exercise control over activities in the Area', including directing and supervising 'a staff of inspectors' and adopting regulations in this context. ${ }^{32}$ The Legal and Technical Commission is not only tasked to make recommendations to the Council in this regard, ${ }^{33}$ but can also be requested by the Council to supervise activities in the Area. ${ }^{34}$ Article 165(3) LOSC provides that members of the LTC 'shall, upon request by any State Party or other party concerned, be accompanied by a representative of such State or other party concerned when carrying out their function of supervision and inspection.' This raises uncertainties with respect to the precise activities to be performed by the LTC. It will be recalled that the LTC only meets twice a year, which could render extensive supervision by the LTC impractical. In any event, no 'staff of inspectors' exists at present and no inspections of exploration activities are carried out. For that to change, the IsA's institutional capacity would need to accommodate inspectors, as further discussed in Section 8.4.2 below.

In summary, the current institutional framework of the ISA facilitates some aspects relevant to the implementation of the precautionary principle but not others. In line with the precautionary principle, a central role is afforded to scientific information, institutionalised through the LTC and supported by

28 Antarctic Treaty (adopted 1 December 1959, entered into force 23 June 1961) 402 UNTS 72, article 7 .

LOSC, articles 62(4)(g), 73(1); FAO Code of Conduct for Responsible Fisheries (adopted 31 October 1995), article 7.7.3.

30 Mary Ann E. Palma, Martin Tsamenyi, and William R. Edeson, Promoting Sustainable Fisheries: The International Legal and Policy Framework to Combat Illegal, Unreported and Unregulated Fishing (Martinus Nijhoff Publishers, 2010), pages 222-226.

31 LosC, articles 136, 137, 140, 153(1).

32 LOsC, articles $162(2)(\mathrm{l}), 162(2)(\mathrm{z})$, annex III article $17(\mathrm{~b})$ (viii).

33 LOsc, article $165(2)(\mathrm{m})$.

34 LOsC, article $165(2)$ (c). 
semi-structured engagement with the scientific community in the form of regular workshops and consultant studies. However, little institutional oversight of the LTC is provided for. This is problematic given the high levels of uncertainty regarding the environmental implications of seabed mining. As concluded in Chapter 2.4.2, precautionary decision-making requires a distinction to be made between scientific advice, uncertainties, and value considerations. The current institutional framework does not provide for such distinction. Furthermore, as discussed in Chapter 7.4.3, it lacks an institutional integration of public participation, be it through surveys or an Ombudsperson within the Secretariat. In addition, the ISA institutional framework does not provide for the mechanisms necessary to ensure compliance by contractors with their obligations under exploration contracts.

\subsection{Current Institutional Limitations}

The previous discussion has clearly illustrated the central role of both the Legal and Technical Commission and the ISA Secretariat in carrying out the assessments and measures required in implementing a precautionary approach. In this respect, the capacity and limitations of each of these organs warrant some discussion.

\subsubsection{Capacity and Limitations of the Legal and Technical Commission}

As discussed above, the Legal and Technical Commission is the central organ responsible for carrying out most of the tasks associated with the implementation of a precautionary approach. While the Council bears the decision-making responsibility, and contractors and external scientists provide environmental advice and expertise, the LTC presides over all technical considerations and assessments relating to the ISA's environmental obligations, ${ }^{35}$ although, its environmental work makes up only a percentage of the LTC's extensive mandate. This presents two challenges: First, the LTC requires detailed expertise in environmental impact assessment and environmental management. Second, the LTC requires the time to be able to carry out its extensive mandate. As the following paragraphs demonstrate, neither of these is currently ensured.

The expertise currently represented in the LTC does not reflect the Commission's far-ranging environmental management competencies. Indeed, at time of writing, only two of the 24 LTC members are environmental scientists 
with expertise in marine ecology. ${ }^{36}$ This has triggered calls for additional expertise in environmental matters. ${ }^{37}$ Without diverse expertise in environmental management and related disciplines, it is difficult to see how the LTC can effectively perform its tasks to assess environmental impacts, recommend protective measures, and respond to environmental emergencies. This lack of environmental management expertise could become particularly problematic in the context of emergency orders, where the LTC must recommend an immediate course of action to prevent serious environmental harm. ${ }^{38}$ At the risk of stating the obvious, the ISA can only discharge its extensive environmental management obligations if its relevant organs, in most cases the LTC, have the capacity and expertise to do so.

This study has identified several measures through which the ISA could better align its decision-making with a precautionary approach, including through: integrating strategic environmental assessments; ${ }^{39}$ providing detailed guidance regarding the requirements for and content of EIAs; ${ }^{40}$ and establishing criteria to evaluate whether an application for an exploration contract provides for 'effective protection and preservation of the marine environment including, but not restricted to, the impact on biodiversity.' ${ }^{\prime 1}$ In order for these measures, and indeed existing measures, to be based on best scientific advice, the expertise represented in the LTC will need to be expanded. Given that ensuring the prevention of serious environmental harm accounts for half of the ISA's mandate, it is arguable that the expertise represented by LTC members should reflect this importance. Indeed, the interim report of the review into the ISA's institutional structure recommends: 'The levels of expertise in both the LTC and the Secretariat required to incorporate applicable standards for the protection and preservation of the marine environment should be increased as appropriate. 42

In addition to a lack of detailed and comprehensive environmental management expertise, the LTC faces time constraints and an unmanageable workload. The LTC only meets two to four weeks per year for which its members

36 For a list of the current members of the LTC, see <http://isa.org.jm/authority/legal-andtechnical-commission>; brief CVs of new LTC members are published by the ISA when the member is elected by the Council.

37 Johnson et al. (n. 8), page 63 .

38 Losc, article 165(2)(k); Nodules Exploration Regulations, regulation 33; Sulphides and Crusts Exploration Regulations, regulation 35.

39 Chapter 7.2.1.

$40 \quad$ Chapters 7.2.3, 7.2.4

41 Nodules Exploration Regulations, regulation 21(4)(b); Sulphides and Crusts Exploration Regulations, regulation 23(4)(b); Chapter 7.2.2.

Johnson et al. (n. 8), page 27 . 
take time out of their professional appointments to serve on the LTC in an honorary capacity. As such, the LTC is not in a position to carry out tasks that require work at any given time, such as emergency orders.

Moreover, facing a significant and increasing workload, the LTC is responsible for: assessing new applications; evaluating environmental impact assessments; developing the Mining Code for the exploitation stage; developing recommendations for diverse topics, including training programmes and the assessment of exploration expenditure; performing the initial functions of the Economic Planning Commission; ${ }^{43}$ overseeing the operation of the Environmental Management Plan for the Clarion-Clipperton Zone and the contractors' monitoring programmes; and recommending adjustments to the Mining Code including regarding environmental standards. With the rise in exploration contracts since 2011, the LTC's workload with respect to evaluating the contractors' annual reports has also increased substantially. As a result, the LTC has been holding two meetings annually since $2013 .{ }^{44}$ Nevertheless, the Commission is faced with an 'overwhelming workload and inadequate time. 45 The ISA institutional review noted concern 'that the Council is currently overtaxing what is essentially a group of unpaid experts, many of whom have other roles and responsibilities. ${ }^{46}$ This trend can be expected to worsen in light of the preparations for the exploitation phase. Indeed, the Secretary-General noted that with respect to the draft framework for the future regulation of mineral exploitation, 'the capacity of the Authority to deliver the outcomes expected by the Commission, within current operational constraints, is limited. ${ }^{47}$

As a result of its overburdened agenda, the LTC has already failed to carry out vital tasks entrusted to it, such as the obligation to 'develop and implement procedures for determining [...] whether proposed exploration activities in the Area would have serious harmful effects on vulnerable marine ecosystems $[\ldots]$ and ensure that, if it is determined that certain proposed exploration activities would have serious harmful effects on vulnerable marine ecosystems, those activities are managed to prevent such effects or not authorized to proceed.48 Although this obligation was established in 2010, as discussed in Chapter 6.4, the LTC has not yet taken up the issue.

43 Chapter 3.4.6.

44 ISA, ISBA/18/C/20 (20 July 2012), paragraph 27.

45 ISA, ISBA $/ 19 / \mathrm{C} / 18$ (24 July 2013), paragraph 9.

46 Johnson et al. (n. 8), page 64 ; see also pages $75^{-76}$.

47 ISA, ISBA/21/A/4 (8 June 2015), paragraph 11.

48 Nodules Exploration Regulations, regulation 31(4); Sulphides and Crusts Exploration Regulations, regulation 33(4). 
In addition, the LTC has not yet been able to address several other important environmentally related matters including developing guidelines on how to operationalise the precautionary approach and best environmental practices $^{49}$ as well as developing risk assessment and risk management standards. ${ }^{50}$ Similar challenges exist with respect to the review and adaptation of protective measures. By way of example, the LTC is required to keep the Environmental Management Plan for the Clarion-Clipperton Zone under review and 'lead the development of environmental standards that will inform the decision and rules to be made if mining activities are seen to affect areas of particular environmental interest. ${ }^{51}$ Precisely how this will be achieved is unclear. Be that as it may, it is clear that developing these standards will only add to the LTC's workload. Consequently, the LTC is already faced with an unmanageable workload, even though test mining and mineral exploitation has not yet commenced.

In short, although affording scientific advice a central role, the current institutional framework neither provides sufficient time for LTC members to exercise this role, nor adequately represents comprehensive and detailed environmental management expertise. Consequently, the current institutional framework is inadequate to secure the full implementation of a precautionary approach to seabed mining. Institutional capacity will therefore need to be increased, in particular in light of the transition to the mineral exploitation phase. ${ }^{52}$

\subsubsection{Capacity and Limitations of the ISA Secretariat}

Since the precautionary approach requires integration into administrative processes and structures, the ISA Secretariat plays an important role in implementing precaution. The Secretariat performs a range of tasks relevant to the implementation of precaution, including developing a Geographic Information System database for the Clarion-Clipperton Zone that integrates contractors' data;53 administering the contracts; conducting stakeholder surveys; preparing annual meetings of the parties including providing background notes; and organising scientific workshops and consultant expert studies. ${ }^{54}$

49 Nodules Exploration Regulations, regulation 31(3); Sulphides and Crusts Exploration Regulations, regulation 33(3).

50 ISA, ISBA/Cons/2015/1 (March 2015), page 42.

$5^{1} \quad$ EMP-CCZ (n. 9), paragraphs 42, 43(g), 46.

$5^{2}$ See also the discussion of ISA member states in this regard: ISA, Press Release, SB-20-7 (17 July 2014).

53 ISA, ISBA/19/A/2 (22 May 2013), paragraph 82.

54 Chapter 3.4.3. 
However, at the time of writing the capacity of the ISA Secretariat is very limited with a mere five natural scientists and four legal experts supporting the work of the ISA on a permanent basis. One may wonder whether this limited capacity might explain, at least in part, the absence of a framework to systematically increase regional environmental baseline data through commissioning and conducting marine scientific research by the ISA itself. As examined in Chapter 6.2, although the ISA has collaborated in some external research projects, much research remains to be done, and the ISA could have already commissioned or indeed conducted this work, if it had the resources and vision to do so.

Demands on the Secretariat will likely grow in the context of rapidly increasing numbers of exploration contracts and the transitioning to the exploitation phase. The Draft Regulatory Framework for Mineral Exploitation in the Area identifies a range of issues regarding which the Secretariat should prepare information and reports, including the definition of the rights of contractors and the obligations of the ISA, as well as a review of best practice with respect to emergency orders. ${ }^{55}$ Moreover, throughout this study, other measures have been identified that could better align the ISA's regulatory framework with the requirements of a precautionary approach. Several of these require additional tasks to be performed by the ISA Secretariat, such as:

- coordinate and commission strategic scientific studies to increase the quality, quantity, and verifiability of environmental baseline data; 56

- organise public participation measures, such as establishing an ombudsperson for present and future generations and coordinating further stakeholder surveys; ${ }^{57}$

- coordinate measures to increase transparency in the ISA's decision-making process, such as the publication of minutes or meeting summaries and any potential video-streaming of ISA meetings. ${ }^{58}$

Moreover, if the ISA opted to conduct the contractors' environmental studies through a centrally coordinated consortium of actors, as discussed above, ${ }^{59}$ this would also have to be coordinated by the Secretariat and potentially supervised by an Environmental Commission, as explored in the following section.

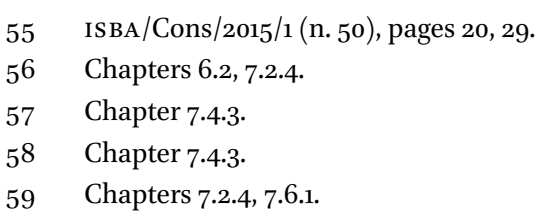


In order to perform these tasks and facilitate precautionary decision-making, the capacity of the ISA Secretariat will need to be increased. ${ }^{60}$ In light of the above, the following sections discuss some specific options for institutional changes to better accommodate precautionary decision-making.

\subsection{Options for Institutional Innovation for the ISA}

In light of the limited institutional capacities of the ISA to facilitate the implementation of the precautionary approach, illustrated throughout this chapter, the following sections discuss some options for institutional development. It will be recalled that the focus of this study is the question whether and in what manner the ISA is currently implementing the precautionary approach, rather than how it could be implementing it. To that end, an exhaustive discussion of institutional innovations is beyond the scope of this study. Nevertheless, two options can be briefly discussed: (1) establishing an Environmental Commission; and (2) establishing a Mining Inspectorate. It is important to note that the establishment of these bodies would not require an amendment of the LOSC, as such evolutionary institutional development is provided for under the Convention. ${ }^{61}$

\subsubsection{An Environmental Commission}

Given the challenges facing the Legal and Technical Commission with regard to workload and expertise its capacities will likely have to be expanded to meet the increasing workload associated with transitioning to the mineral exploitation phase. Some respondents to the review of the ISA's institutional structure 'suggested that the LTC could mandate environment and/or scientific committees with experts in specific fields to take on some of its technical work and at the same time include consultative and transparent access. ${ }^{62}$ While this would enlarge the capacity of the LTC, it is questionable whether that will be sufficient, particularly in light of the current lack of transparency, public participation, and availability outside of formal meetings times, which makes it difficult to carry out supervision of activities in the Area and respond to environmental emergencies. Indeed, the aforementioned review recommends 'restricting and re-focusing the remit of LTC.' Consideration should be given to the establishment of 'other Commissions and the setting up of an independent inspectorate

\footnotetext{
6o See also Johnson et al. (n. 8), pages $5 \mathbf{1}^{-54}$.

$61 \quad$ LosC, articles 158(3); 16o(2)(d); 162(2)(d); 166(1), 167(1).

62 Johnson et al. (n. 8), page 65 .
} 
or enforcement body that could relieve the LTC of part of its work relating to regulation and enforcement'. ${ }^{63}$

One option could be to allocate some of the LTC's responsibilities to a different, permanent ISA organ. Indeed, the aforementioned ISA Technical Study makes the case for a permanent body:

The ISA should form a permanent committee to address the clear and urgent need to rationalize and incorporate past and present environmental rules, regulations and requirements with, and within, the evolving exploitation frameworks for [polymentallic nodules] and other metal resources within the Area. ${ }^{64}$

The Study stresses the need to move beyond ad hoc activities to establish 'a 'competent' body providing continuity across differing resources.' It also argues 'that it would benefit the ISA if industry recognizes that there is a formal, continuing and identified group monitoring their activities. 65

An Environmental Commission could institutionalise these recommendations. This Commission could consist of independent experts possessing extensive relevant expertise including in marine conservation and ecology, environmental management, environmental impact assessment, adaptive management, and environmental law. In contrast to the LTC, at least some of the members of the Environmental Commission could be permanent staff. This would allow the Commission to respond immediately if an emergency order is warranted and advise the Secretary-General on which immediate measures would be necessary. ${ }^{66}$ It would also enable the Commission to supervise environmental baseline studies and monitoring programmes by contractors on a continual basis and provide a dedicated point of contact for contractors with respect to environmental management of the contractors' activities.

An Environmental Commission could also be tasked to develop and ensure the implementation of the environmental measures and principles set out in the Mining Code. To this end, the Commission would be responsible for ensuring that measures to protect vulnerable marine ecosystems are developed without delay and that additional regional environmental management

63 Johnson et al. (n. 8), page 68.

64 Clark, Cook Clark, and Pintz (n. 7), page 79.

65 Ibid.

66 Chapters 5.4.4, 6.6; Nodules Exploration Regulations, regulation 33; Sulphides and Crusts Exploration Regulations, regulation 35 . 
plans are established, as has been requested by the Council. ${ }^{67}$ Similarly, the Commission could develop and recommend to the Council a strategy for the implementation of a precautionary approach, as required by the Mining Code. ${ }^{68}$ The Commission could also conduct strategic environmental assessments to enable ecosystem-based regional and global environmental management. ${ }^{69}$

The Environmental Management Plan for the Clarion-Clipperton Zone envisages adaptive management, ${ }^{70}$ which the Environmental Commission could coordinate through the conduct of frequent re-assessments of environmental factors and protective measures. In light of these assessments, the Commission could be tasked to develop and update the regulatory framework with respect to environmental protection, in coordination with the LTC.

In this context, an important question is how the Environment Commission's decisions would be incorporated into the procedural framework. The danger is that if environmental tasks are 'outsourced' to a separate body but its decisions do not carry the same weight as those of the LTC, environmental considerations might be marginalised. Yet the ISA's extensive environmental obligations require environmental considerations to assume a central role in the decision-making framework. As such, recommendations by the Environmental Commission regarding the aforementioned tasks but also amendments to the Mining Code should carry the same weight as those of the LTC and should be transmitted to the Council.

This leads to one of the most crucial tasks the Environmental Commission could perform, that is the assessment of whether an application for a plan of work provides for effective environmental protection, which is a prerequisite to the LTC recommending approval of an application. ${ }^{71}$ In doing so, the Environmental Commission could address the transparency concerns examined in Chapter 7.4. While the LTC could continue to assess the technological and financial capabilities of an applicant in closed session, the Environmental Commission could hold open meetings, manage the process of evaluating EIAS and coordinating an independent review of the EIA, ${ }^{72}$ and publish both strategic environmental assessment and environmental impact assessment reports,

\footnotetext{
67 Chapter 6.3; ISA, ISBA/20/C/L.10 (21 July 2014), paragraph 9.

68 Nodules Exploration Regulations, regulation 31(3); Sulphides and Crusts Exploration Regulations, regulation 33(3).

69 Chapter 7.2.1.

$70 \quad$ EMP-CCZ (n. 9), paragraphs 30-31.

$71 \quad$ Nodules Exploration Regulations, regulation 21(4)(b); Sulphides and Crusts Exploration Regulations, regulation 23(4)(b); Chapter 3.5.2.

72 Chapter 7.2.3.
} 
all of which would contribute to the transparency of the basis on which an application is approved, modified, or rejected. This would also ensure that risk assessment and environmental management procedures are afforded adequate time and attention, something that may prove an insurmountable challenge if conducted solely by the LTC, particularly given the increasing range of other assessments needed to be conducted by the LTC relating to new applications. What becomes clear is that this Commission would assume a range of time-consuming tasks, which at present rest with the LTC and which are at risk of being jeopardised in the context of unmanageable workloads and insufficient expertise.

The proposed Environmental Commission could be established as a permanent subsidiary body to the Council, alongside the LTC, pursuant to LOSC Articles 158 and $162(2)(d)$. Indeed, a number of respondents to the review of the ISA's institutional structure noted that the Council 'should give more attention to exercising its right to establish new subsidiary organs. ${ }^{73}$ The Environmental Commission should closely cooperate with and complement the LTC's work, especially in relation to assessing new applications, reviewing the contractors' annual reports, and developing the Mining Code. Although compartmentalising these tasks into environmental, financial, and technical consideration inevitably leads to overlap, the LTC routinely separates into working groups to streamline their tasks. ${ }^{74}$ In fact, recognising the importance of its environmental mandate, the LTC previously set up a working group 'to consider environmental issues in a broader context within the scope of its mandate. ${ }^{75}$ As such, allocating its environmental work to a specific commission could prove relatively uncomplicated. Nonetheless, overlap could be expected in the context of assessing future applications for commercial-scale mining, with respect to an applicant's feasibility study, closure plan, and indeed financial plan indicating the allocation of financial resources to particular activities. This could be addressed through clear guidelines regarding the responsibility of each ISA organ as well as close collaboration between the LTC and the Environmental Commission.

With these parameters in mind, an Environmental Commission would be an important institutional innovation to ensure that the ISA's extensive mandate for environmental conservation can be adequately implemented.

\subsubsection{A Mining Inspectorate}

While an Environmental Commission could address some of the institutional limitations of the Legal and Technical Commission, it will be readily apparent

73 Johnson et al. (n. 8), page 48.

74 See for example ISA, ISBA/17/C/13 (13 July 2011), paragraph 5 .

75 ISA, ISBA/11/C/8 (19 August 2005), paragraph 31. 
from the foregoing discussion that the capacity and structure of the ISA Secretariat will also have to be revisited in the context of the transition to test mining and mineral exploitation. In particular, changes to the structure of the Secretariat will likely be required to enable the ISA to effectively carry out its extensive mandate to ensure contractors comply with their obligations. ${ }^{76}$

As discussed in Section 8.2.2 above, monitoring compliance using satellite data, video footage, or other technology would require teams of technical experts within the Secretariat to oversee the implementation of the technology and evaluate the data. What is more, giving effect to the ISA's competence to inspect installations in the Area exceeds the current capacity of the ISA.

Against this background, the ISA Technical Study No. 11 recommends the establishment of a permanent Mining Inspectorate that could give effect to the ISA's mandate to monitor compliance of contractors, including carrying out inspections. This new Mining Inspectorate could comprise a Mining Registry, a Compliance Office, a Data and Archive Centre and an Inspector General's Office. ${ }^{77}$ A Compliance Office could carry out the aforementioned tasks of utilising technological tools to monitor compliance by contractors.

Precedents for inspectorates can be found in international organisations working in the field of disarmament, such as the Organisation for the Prohibition of Chemical Weapons (OPCW) and the International Atomic Energy Agency (IAEA). The latter has a staff of inspectors within its Secretariat who can perform inspections to ensure a state's nuclear facilities 'are not used in such a way as to further any military purpose. ${ }^{78}$ In addition to using satellite images, the IAEA has performed over 2700 in-field inspections in $2014 .{ }^{79}$ Any cases of non-compliance are reported the Director-General of the IAEA who transmits the information to the Board of Directors, which then reports noncompliance to the UN and can impose sanctions. ${ }^{80}$ The Board of Directors is broadly comparable to the ISA Council, as it is the executive organ of the IAEA that comprises representatives from 35 member states, who meet several times per year.

76 Chapters 3.6.1.

77 Clark, Cook Clark, and Pintz (n. 7), page 78.

78 Statute of the International Atomic Energy Agency (adopted 23 October 1956, entered into force 29 July 1957, amended 23 February 1989) 276 UNTS 3, article III(A)(5).

79 See the figures published by IAEA <https://www.iaea.org/safeguards/basics-ofiaea-safeguards/safeguards-facts-and-figures $>$.

$80 \quad$ Statute of the International Atomic Energy Agency, article XII(C). 
A similar regime of compulsory inspections has been established for the OPCW, in order to achieve the elimination of chemical weapons. ${ }^{81}$ The OPCW uses a form of self-reporting by the member states as well as inspections to verify the information reported. ${ }^{82}$ In addition to routine inspections, and those carried out in case of alleged use of chemical weapons, the OPCW can carry out challenge inspections 'of any facility or location in the territory or in any other place under the jurisdiction or control of any other state party for the sole purpose of clarifying and resolving any questions concerning possible noncompliance with the provisions of this Convention. ${ }^{83}$ The opcw Inspectorate forms part of the organisation's 'Technical Secretariat' 84 and comprises around 200 inspectors, who are all independent experts. ${ }^{85}$

Similar to the OPCW, an inspection system by the ISA would likely utilise self-reporting by the contractors together with inspections to verify the reported information. It is important that inspection of a contractor's activities would not depend on direct financial support by that contractor. Rather, a Mining Inspectorate would need to be either cross-funded by all contractors or ISA member states. In the case of the latter, the problem discussed in Chapter 3.7 could persist, whereby all member states finance the mining activities of some operators and state parties. Whether states consent to such a funding mechanism could largely depend on the existence of adequate benefit sharing mechanisms, envisaged in the $\mathrm{LOSC}^{86}$ to ensure at least some of the benefits are reaped by mankind.

Furthermore, should the Enterprise be able to conduct mining operations in the future, as envisaged by the LOSC, ${ }^{87}$ this could create a conflict of interest whereby the ISA Inspectors would have to monitor compliance of another ISA organ, the Enterprise. In this regard, although the call for an Inspectorate was echoed by the review of the ISA's institutional structure, some participants of

81 Convention on the Prohibition of the Development, Production, Stockpiling and Use of Chemical Weapons and on Their Destruction (adopted 3 September 1992, entered into force 29 April 1997) 1974 UNTS 45, preamble.

82 Ibid., articles IV(7), v(9), vi(8), 'verification annex.'

83 Ibid., article $\mathrm{IX}(8)$.

84 Ibid., part D.

85 Henry G. Schermers and Niels M. Blokker, International Institutional Law (Martinus Nijhoff Publishers, 2011), page 893 .

86 LOSC, articles 82(4), 140(2), 151(10), 160(2)g), 173(2); Agreement Relating to the Implementation of Part XI of the United Nations Convention on the Law of the Sea (adopted 28 July 1994, entered into force 28 July 1996) 1836 UNTS 3, annex section 7 .

87 LOsC, articles 170(1), annex IV article 1; Chapter 3.4.7. 
the review suggested it should be an independent body 'to prevent conflict of interest between the licensing authority and the Inspectorate.'88

The IAEA faces a comparable problem, as its inspectors, who report to the Director-General of the organisation, are also tasked to inspect all operations by the Agency itself, to ensure inter alia that 'the Agency is taking adequate measures to prevent the source and special fissionable materials in its custody or used or produced in its own operations from being used in furtherance of any military purpose. ${ }^{\prime 89}$ However, as Schermers and Blokker observe: 'as the responsibility of the Director-General for the operations of the organization is limited, undue pressure on the inspectors seems unlikely. The advantages in their forming part of an established secretariat outweigh the drawbacks of their partial dependence on the Director-General. ${ }^{90}$ The same might be true for the ISA. An Inspectorate would likely report to the Council, which is tasked to 'exercise control over activities in the Area, ${ }^{91}$ including directing and supervising inspections. ${ }^{92}$ Member states would thus have an opportunity to scrutinise the work of the Mining Inspectorate. Moreover, transparency over non-proprietary information, such as compliance by contractors with environmental obligations, would further limit potential conflicts. What remains unclear is the extent to which the Legal and Technical Commission will be able to be supervise activities in the Area and potentially also inspectors, given its already high workload. However, the reallocation of some of the LTC's tasks to an Environmental Commission might enable the LTC to find time to carry out its supervisory role, if requested by the Council to do so.

As has become clear, giving effect to the ISA's mandate to monitor compliance by contractors including through on-vessel inspections will likely be an operational challenge requiring significant resources and capacity. Establishing an Inspectorate within the ISA Secretariat would both provide capacity and expertise to develop the ISA's inspection mandate.

\subsection{Conclusion}

This chapter has examined the ISA's institutional structure and capacity against the need to implement a precautionary approach to seabed mining.

\footnotetext{
88 Johnson et al. (n. 8), page 51.

$89 \quad$ Statute of the International Atomic Energy Agency, article XII(B).

9o Schermers and Blokker (n. 85), page 891.

91 LOsC, article $162(2)(\mathrm{l})$.

92 LOsC, article $162(2)(\mathrm{z})$.
} 
As highlighted at the outset, institutional capacity is crucial to facilitate precautionary decision-making and implement and enforce environmental standards and protective measures.

As the chapter has demonstrated, in line with the precautionary approach, the current institutional framework provides a central role for scientific advice, through the Legal and Technical Commission. Semi-structured engagement with the wider scientific community occurs through workshops and consultant studies. However, in addition to privileging scientific advice, precautionary decision-making also requires the identification of uncertainties, particularly in the context of selecting protective measures and indeed strategic environmental objectives. These must be informed by subjective judgments as to the value placed by the public on deep ocean minerals, ecosystems, and biodiversity..$^{93}$ Contrary to these requirements, the ISA's current structure provides for little institutional oversight of the LTC and lacks an institutional integration of public participation, be it through surveys or an Ombudsperson within the Secretariat. In addition, the ISA institutional framework does not provide for the mechanisms to ensure compliance by contractors with their obligations under exploration contracts. Neither the LTC, nor the Secretariat, currently has the capacity to monitor compliance.

As this illustrates, the most important institutional shortcomings relate to the LTC and the ISA Secretariat. In particular, the LTC already faces an unmanageable workload and insufficient time during its two short annual meetings. Moreover, with only two of its 24 members being experts in environmental science and marine ecology, the LTC fails to represent the detailed and comprehensive expertise that would be necessary to discharge its numerous environmental tasks. The Secretariat faces similar shortcomings of very limited capacity with a mere five natural scientists and four legal experts supporting the work of the ISA on a permanent basis. As the ISA Technical Study No.11 highlights, the ISA will need to transition from an international organisation that provides meeting services for its states parties, to an administrative agency that organises, carries out, and controls seabed mining activities in the Area. ${ }^{94}$

Consequently, the current institutional framework is inadequate to secure the full implementation of a precautionary approach to seabed mining. To return to the initial questions posed in the introduction to this chapter, it is clear that although the ISA' institutional structure facilitates elements of the precautionary approach to some degree, such as the integration of scientific advice into the decision-making process, several shortcomings remain. Some

93 Chapter 2.4.2.

94 Clark, Cook Clark, and Pintz (n. 7), pages 78-79; LOSC, article 153(1). 
of the substantive and procedural challenges to implementing a precautionary approach, identified in Chapters 6 and 7 , can, indeed, be explained by reference to the ISA's institutional capacity. For example, although foreseen in the Mining Code, the protection of vulnerable marine ecosystems from mineral exploration work has not yet been addressed owing to the LTC's unmanageable workload and the absence of any other entity tasked with carrying out this work. One can only speculate as to whether other aspects of the ISA's work, including cooperation on multi-purpose marine protected areas, further regional environmental management plans, emergency orders, best environmental practices, transparency, and strategic environmental assessments and EIAS, would be further advanced if it was not for the ISA's institutional limitations. Against this background, it is inevitable that adoption and implementation of further environmental obligations will fall behind once the test mining and exploitation phase commences, unless the ISA's institutional capacity is increased.

These shortcomings can be partly explained by a lack of strategic vision for the ISA, which must include adjustments of the institutional structure to match the evolving tasks of the Authority.

A consequence of not having such a document is that priorities within the technical work lack sufficient impetus and their execution is not sufficiently signalled or pre-planned. Consequently tight deadlines and extra work becomes an imposition on 'unpaid' nominees (e.g. LTC) who then lack sufficient time to tackle complex and difficult tasks. ${ }^{95}$

Leaving aside the practical and real world constraints imposed by finances and politics, this chapter has discussed two possible institutional changes that might be adopted as a means of improving the performance of the ISA and better institutionalising its ability to effectively implement a precautionary approach. First, it has been proposed that an Environmental Commission could carry out the ISA's environmental obligations and thereby unburden the LTC. The objective would be for this Commission to rectify the shortcomings identified in relation to the LTC, such as having a more permanent presence and representing wide-ranging expertise relevant to environmental impact assessments and management. Second, a permanent Mining Inspectorate within the Secretariat, as suggested in the ISA Technical Study No. 11, will likely be required to carry out the ISA's mandate with regard to ensuring that contractors comply with all obligations.

95 Johnson et al. (n. 8), page 73 . 